D.O.I: $10.3895 /$ gi.v10i2.1607

\title{
PLANEJAMENTO SISTEMÁTICO DE LAYOUT APLICADO À MANUFATURA: UM ESTUDO DE CASO NO POLO NAVAL DE RIO GRANDE
}

\section{SYSTEMATIC LAYOUT PLANNING APPLIED TO MANUFACTURING: AN ILLUSTRATED CASE AT BRAZILIAN NAVAL HUB}

\author{
André Andrade Longaray ${ }^{1}$; Deborah Matheus das Neves Fiussen ${ }^{2}$ \\ ${ }^{1}$ Universidade Federal do Rio Grande - FURG - RS \\ longaray@yahoo.com.br \\ ${ }^{2}$ Universidade Federal do Rio Grande - FURGN - RS \\ dfiussen@gmail.com
}

\begin{abstract}
Resumo
O presente trabalho descreve a aplicação metodologia do Planejamento Sistemático de Layout (SLP) para a elaboração de um modelo de layout em uma empresa fabricante de luminárias marítimas, localizada no Polo Naval de Rio Grande, no Rio Grande do Sul. Por meio do emprego do setup teórico que instrumentaliza o SLP foram realizados os procedimentos de levantamento do ambiente de trabalho, das movimentações de materiais em processamento, das operações mais utilizadas e seu impacto na produção. Além disso, verificaram-se os espaços necessários para os postos de trabalho, bem como a necessidade de sua proximidade. Foi possível destacar as células produtivas e verificar os fluxos entre elas, resultando na elaboração de dois modelos de layout exequíveis, levando em consideração as limitações das instalações da organização. Na sequência, foi realizada a avaliação ponderada dos modelos e selecionado o que melhor se adequou ao caso em estudo. Tais avaliações possibilitaram a proposição da aplicação de um modelo de layout baseado no SLP para a empresa.
\end{abstract}

Palavras-chave: arranjo físico; célula de produção; planejamento sistemático de layout.

\section{Introdução}

No atual mercado fabril brasileiro, a otimização do processo produtivo tem se configurado em uma condição essencial para as indústrias que desejam ser competitivas. Isso tem acarretado em um aumento de esforços e investimentos na busca pelo aperfeiçoamento do planejamento e controle da produção, por meio da adoção de uma diversidade de práticas, tais como os programas de gerenciamento da rotina, as políticas de gestão de estoque de matérias-primas bem como as técnicas de projeto de arranjo físico da produção.

No que tange especificamente ao arranjo físico da produção, também chamado de layout produtivo, esse proporciona que os equipamentos e as instalações atendam as necessidades de produção das empresas, garantindo a sequência de atividades, diminuindo distâncias e suavizando o 
fluxo de materiais. Possibilita ainda, a diminuição dos estoques e a redução do tempo de espera nas filas.

Sob essa perspectiva, o presente trabalho tem por objetivo descrever a aplicação da metodologia do Planejamento Sistemático de Layout (Systematic Layout Planning) proposta por Muther (1978) na elaboração de um modelo de design produtivo em uma empresa fabricante de luminárias marítimas que possui seu arranjo estabelecido em células de produção com fabricação em lotes de produtos.

A empresa objeto deste estudo produz uma luminária de led marítima que se destaca por ser uma inovação no mercado e atender ao polo naval de Rio Grande. O fator que a diferencia em relação às luminárias fabricadas pela concorrência é sua proteção contra as intempéries, o que fornece a possibilidade de utilização em localidades banhadas pelo mar ou dentro dele, sem que a salinidade afete seu funcionamento. Outro item relevante é que ela é feita com lâmpadas de led que geram luz de cor branca proporcionando baixo custo de energia. Possui também uma bateria interna recarregável com tempo de vida útil relativamente grande.

Esta pesquisa tem como justificativa prática a busca por um modelo de produção que forneça a capacidade produtiva necessária para que a empresa em questão possa expandir seu mercado de atuação, hoje restrito à demanda geográfica local. Além disso, pretende propiciar informações que sirvam de benchmarking para o processo de seleção de designs produtivos para outras microempresas, segmento em que há restrições inerentes ao tamanho e faturamento.

No âmbito teórico o estudo se justifica ao fazer uso da base teórico metodológica do Planejamento Sistemático de Layout proposta por Muther (1978), em um contexto organizacional específico, corroborando com outros trabalhos sobre o tema (TOMPKINS, WHITE \& BOZER, 1996; YANG, SU \& HSU, 2000; MARUJO, CARVALHO \& LEITÃO, 2010; SANTOS, GOHR \& LAITANO, 2012).

Para alcançar o objetivo proposto, este trabalho está organizado em seis seções. Estabelecido o marco introdutório, a seção dois conceitua arranjo físico e sua tipologia. A seção três discorre sobre a técnica do Planejamento Sistemático de Layout. Na sequência, a seção quatro apresenta os procedimentos metodológicos da pesquisa. A seção cinco descreve a proposta de elaboração do layout produtivo da empresa analisada. Por fim, a seção seis tece as considerações finais a respeito dos resultados obtidos, das limitações e das recomendações do estudo.

\section{Arranjo físico da produção}

O arranjo físico, de acordo com Slack, Johnston e Chambers (2009), é a preocupação com o posicionamento físico dos recursos de transformação, uma das características mais evidentes de uma operação produtiva. Esses autores destacam que, alterações no design podem afetar os fluxos 
de materiais e pessoas, causando alterações nos custos e na eficácia do processo produtivo e, desta forma pode ser utilizado como fator estratégico.

Quanto aos seus objetivos, pode-se dizer que o arranjo físico da produção tem por meta encontrar a combinação ótima das instalações, harmonizando a produção com a melhor utilização do espaço físico disponível, derivando em um processamento mais efetivo, através da menor distância, no menor tempo possível (JUNIOR, ANDRADE \& CARMO, 2012).

Três pressupostos viabilizam a consecução desse propósito: as inter-relações, que consistem em uma dependência ou proximidade entre as atividades; o espaço, que é quantidade, tipo, forma e configuração dos itens; e, o ajuste, que trata do arranjo dos equipamentos, independente do produto, processo ou extensão do projeto (ROSI, LOUREIRO \& FERREIRA FILHO, 2010).

Quanto aos tipos de arranjos físicos descritos na literatura, pode-se citar o arranjo por produto ou linha (flow shop), arranjo por processo ou funcional (job shop), arranjo por posição fixa, o arranjo celular e o arranjo misto (MARTINS \& LAUGENI, 2005).

O arranjo por linha é fixo e orientado para o produto; os postos de trabalho estão em sequencia de operações de acordo com o produto. Esta solução é adequada para um produto ou produtos similares, pois geralmente o processo é simples, rápido e inflexível.

No arranjo por processo, os equipamentos são agrupados de acordo com suas especialidades. Neste caso, os produtos em processamento se deslocam ao local para serem transformados de acordo com sua necessidade, podendo passar por um mesmo grupamento mais de uma vez. Este tipo de layout exige profissionais com conhecimentos técnicos específicos e em nível alto de conhecimento (MATOS, MARIANO \& ALMEIDA, 2010).

Já no arranjo por posição fixa, o material em processamento fica parado e as pessoas e recursos é que se locomovem. Geralmente é utilizado em grandes projetos, como na construção de um prédio, em que o resultado é um único produto com muitos componentes (JUNIOR, ANDRADE \& CARMO, 2012).

Por fim, o design celular, ou arranjo físico por célula de produção, é aquele que concentra em um mesmo espaço todos os recursos necessários à fabricação de um determinado produto antecipadamente escolhido, de forma que, neste formato de organização o espaço percorrido pelo produto dentro da indústria seja diminuído (MARTINS \& LAUGENI, 2005).

No layout celular é possível combinar a união das vantagens dos arranjos por processo e por produto. As ferramentas necessárias são dispostas próximas umas das outras e na sequência adequada ao processo de produção, sendo assim, este layout apresenta flexibilidade, sendo possível fabricar vários tipos de produtos que possuem características similares (PRATA, 2002).

Outro beneficio do arranjo celular é a rapidez da identificação dos problemas que ocorrem na produção (SLACK, JOHNSTON \& CHAMBERS, 2009). 
Por fim, uma última possibilidade de arranjo físico diz respeito ao arranjo físico misto. A principal característica deste é que o mesmo combina elementos de alguns ou de todos os demais tipos básicos de arranjo.

\section{Planejamento sistemático de layout}

O Sistematic Layout Planning (SLP) é uma metodologia proposta por Richard Muther (1978), cujo propósito é auxiliar na condução de projetos de arranjo físico, de forma estruturada, facilitando a visualização dos elementos envolvidos no processo produtivo (TOMPKINS et al, 1996).

Para efeitos de operacionalização do SLP, Muther e Wheeler (2000) sugerem que, preliminarmente, seja feito um checklist das variáveis Produto, Quantidade, Roteiro, Serviços de Suporte e Tempo do contexto em estudo. Tal análise representa o levantamento dos dados de entrada e precede a utilização propriamente dita da metodologia.

A partir do levantamento dos dados de entrada, o SLP sistematiza o arranjo da produção, baseado em quatro etapas (MUTHER \& WHEELER, 2000): i) localização; ii) layout físico geral; iii) layout físico detalhado; e iv) implantação.

A primeira etapa, de localização, promove as ações para a definição do local físico a ser utilizado. Na segunda etapa, layout físico geral, importa estabelecer o fluxo de materiais, o posicionamento relativo entre as atividades do processo, o exame entre o espaço necessário e o disponível, e a elaboração do diagrama de relações entre áreas. $\mathrm{Na}$ terceira etapa, layout físico detalhado, Yang et al (2000) explicita que devem ser delineadas propostas para a nova configuração da localização das máquinas e equipamentos, bem como de toda a infraestrutura física. Por fim, a quarta etapa da metodologia SLP, implantação, se refere à avaliação das propostas geradas e escolha daquela que será adotada (MUTHER, 1978).

Para que haja êxito na sua consecução, Muther (1978) embasa as quatro etapas da metodologia do SLP na observância de três conceitos fundamentais:

I) inter-relações - indica o grau relativo de proximidade ou dependência entre as atividades do processo produtivo;

II) espaço - indica as condições de quantidade, tipo e forma de configuração dos itens a serem posicionados; e

III) ajuste - adequação do arranjo físico em função das áreas e equipamentos visando a otimização do processo produtivo. 
Nesse contexto, a presente pesquisa tem por objetivo a utilização do SLP para o estudo do arranjo físico atual e a proposição de um novo layout orientado à otimização do processo produtivo na empresa objeto de intervenção deste trabalho.

\section{Procedimentos metodológicos da pesquisa}

A presente seção expõe o delineamento metodológico da pesquisa. Classifica o trabalho quanto à finalidade, natureza, fonte de coleta de dados, abordagem metodológica e o instrumento de intervenção empregado.

No que tange a sua finalidade, a pesquisa enquadra-se como um estudo exploratório. De acordo com Gil (2002), estudos exploratórios tem o objetivo principal de desenvolver ideias e conduzir a procedimentos relativamente sistemáticos para a obtenção de observações empíricas, bem como possibilitar a identificação das relações entre os fenômenos estudados. Tal perspectiva se alinha com o objetivo desta pesquisa, de descrever a aplicação da metodologia do Planejamento Sistemático de Layout (Systematic Layout Planning) proposta por Muther (1978) na elaboração de um modelo de design produtivo em uma empresa fabricante de luminárias marítimas que possui seu arranjo estabelecido em células de produção com fabricação em lotes de produtos.

Quanto à sua natureza, esta pesquisa se caracteriza como um estudo de caso. O estudo de caso foi realizado em uma microempresa do setor eletro-eletrônico, localizada no Polo Naval do estado do Rio Grande do Sul. A referida organização possui 23 funcionários e produz sete tipos de luminárias para uso industrial e naval. Dentre os produtos idealizados pela empresa, merece destaque o SICC (Sistema de Iluminação para Captura de Camarão).

Como fonte de coleta de dados, o trabalho emprega entrevistas, análise documental e pesquisa bibliográfica (GIL, 2002). Foram realizadas entrevistas não estruturadas para a obtenção dos dados primários e o levantamento de documentos e pesquisa bibliográfica como fonte de dados secundários.

A abordagem metodológica do trabalho é quali-quantitativa. Gil (2002) defende a ideia de combinar métodos quantitativos e qualitativos, com intuito de proporcionar uma base contextual mais rica para interpretação e validação dos resultados de uma pesquisa. Sob essa ótica, o presente estudo é qualitativo nas etapas de levantamento dos dados primários e secundário e quantitativo nas demais etapas.

O instrumento de intervenção empregado no estudo de caso foi o Systematic Layout Planning (SLP) proposto por Muther (1978). O SLP se operacionaliza por meio de um levantamento prévio de dados - $(\mathrm{P}),(\mathrm{Q}),(\mathrm{R}),(\mathrm{S})$ e $(\mathrm{T})$ - e por quatro etapas (localização, layout geral, layout específico e implantação), que ocorrem de forma sistemática e sistêmica. 


\section{Descrição da proposta de uso do SLP}

Esta seção discorre sobre os procedimentos adotados pelos pesquisadores para o desenvolvimento do layout produtivo da empresa objeto do estudo de caso tomando por base o levantamento dos dados de entrada (produto, quantidade, roteiro, serviço de suporte e tempo) e, subsequentemente, as etapas descritas na metodologia do Planejamento Sistemático de Layout: localização, layout geral, layout detalhado e implantação.

\subsection{Levantamento dos dados de entrada}

Inicialmente, foi procedido o levantamento dos dados de entrada de (P) produto, (Q) quantidade, $(\mathrm{R})$ roteiro, $(\mathrm{S})$ serviço de suporte e $(\mathrm{T})$ tempo para a empresa pesquisada.

\section{(P) produto}

De acordo com Matos, Mariano e Almeida (2010), os produtos ou materiais são matériasprimas, componentes adquiridos, produtos semiacabados ou finais, que de alguma forma são processados dentro da empresa. Para Muther (1978), produto é simplesmente o que é preciso ser produzido ou feito.

No caso em questão, o produto manufaturado na empresa corresponde a uma luminária de led de pequeno porte indicada para o uso marítimo.

\section{(Q) quantidade}

A quantidade se refere às medidas usadas para dimensionar o volume da produção, tais como número de produtos, toneladas, metros, valor produzido ou de venda (MATOS, MARIANO \& ALMEIDA, 2010)

No que tange ao presente estudo de caso, a empresa produz mensalmente a média de 1.000 (mil) unidades de luminárias de led marítimas.

O uso de matérias-primas corresponde ao descrito no Quadro 1 - Levantamento de matérias primas. 
Quadro 1 - Levantamento de matérias primas

\begin{tabular}{|l|l|}
\hline Materiais utilizados para a produção & Quantidade média em um mês \\
\hline 1. Resistores SMD 1/4w 1206 & 11000 unidades \\
\hline 2. Capacitor SMD multicamadas 1206 & 1000 unidades \\
\hline 3. Foto transistor 5mm & 1000 unidades \\
\hline 4. Transistor SMD BC817 & 7000 unidades \\
\hline 5. Diodo 1N4007 SMD & 1000 unidades \\
\hline 6. Led branco 10mm & 6000 unidades \\
\hline 7. Led vermelho 5mm & 1000 unidades \\
\hline 8. PCI 3cm/3cm & $9000 \mathrm{~cm}^{2}$ \\
\hline 9. Cabo com conector & 2000 unidades \\
\hline 10. Cano de PVC esgoto 50mm corte 5cm & $5000 \mathrm{~cm}$ \\
\hline 11. Borracha silaex & $40000 \mathrm{ml}$ \\
\hline 12. Corda para fixação 1,5mt & $10 \mathrm{rolos}$ \\
\hline 13. Solda & $10 \mathrm{~kg}$ \\
\hline 14. Sorinho & $1 \mathrm{rolo}$ \\
\hline
\end{tabular}

Fonte: Pesquisa de campo (2013)

\section{(R) roteiro}

$\mathrm{O}$ roteiro diz respeito às movimentações de materiais e pessoas (operações) que devem ocorrer durante os processos de fabricação.

Um método para delinear o roteiro é a realização da ordenação das operações envolvidas (rol de operações), onde são listadas todas as etapas componentes da produção (FITZSIMMONS \& FITZSIMMONS, 2010).

Sob essa perspectiva, os pesquisadores identificaram o rol de operações para o produto luminária de led, conforme demonstrado no Quadro 2 - Rol de operações para a produção da luminária de led.

Quadro 2 - Rol de operações de atividades para produção de luminárias de led

\begin{tabular}{|l|}
\hline 1. SERIGRAFIA PCI \\
\hline 2. CORROSÃO PCI \\
\hline 3. VERNIZ PCI \\
\hline 4. FURAÇÃO PCI \\
\hline 5. SOLDAGEM SMP \\
\hline 6. CORTE PCI \\
\hline 7. SOLDAGEM LEDS \\
\hline 8. CORTE GABINETE \\
\hline 9. FURAÇÃO DO GABINETE \\
\hline 10. FIXAÇAO PCI \\
\hline 11. TESTE \\
\hline 12. COLOCAÇÃO BORRACHA \\
\hline 13. LIMPEZA \\
\hline 14. TESTE FINAL \\
\hline 15. ESTOQUE \\
\hline 16. ADMINISTRAÇÃO \\
\hline 17. RECEBIMENTO $\backslash$ EXPEDIÇÃO \\
\hline Fonte: Pesquisa de campo (2013)
\end{tabular}


O Quadro 2 permite aferir que as atividades de produção da luminária ocorrem em 17 (dezessete) fases, iniciando pela atividade "preparação para serigrafia PCI (Placa de Circuito Interno)" e encerrando com a atividade "recebimento/expedição".

\section{(S) serviço de suporte}

Serviços de suporte são os recursos, atividades bem como funções auxiliares que devem suprir o processo e que lhe proporcionará condições de funcionamento efetivo. Estão inclusos nesses, as máquinas, ferramentas, alimentação, setores de escritório e demais instrumentos de apoio à produção (COSTA, 2004).

A empresa estudada possui um total de 23 funcionários, sendo que, 18 (dezoito) desses envolvidos diretamente no processo de produção das luminárias de led.

A jornada semanal de 40 horas de trabalho, com turnos de empregados trabalhando de segunda à sexta-feira, entre 7 (sete) e 19 (dezenove) horas, observando-se os intervalos previstos na legislação trabalhista vigente.

A parte contábil e de folha de pagamento não são realizadas na empresa, ficando ao encargo de serviço terceirizado.

Quanto às máquinas e ferramentas, a organização possui em seu patrimônio tornos, fresadoras, furadeiras e aparelhos de solda bem como algumas ferramentas desenvolvidas de forma customizada para a produção das luminárias de led.

O trabalho de prospecção dos produtos está a encargo dos dois sócios. Os mesmos são responsáveis pelas visitas de demonstração e de venda dos produtos.

\section{(T) tempo}

O quesito tempo a ser observado na entrada de dados para o SLP concerne aos prazos para a execução do plano de produção, os tempos de operação para as funções produtivas e a determinação das prioridades e urgências de ações para a manutenção do ritmo de produção (MUTHER, 1978).

Neste estudo de caso, especificamente, a produção das luminárias ocorre observando-se os tempos descritos no Quadro 3 - Levantamento do setup e processamento da produção. 
Quadro 3 - Levantamento do setup e processamento da produção

\begin{tabular}{|c|c|c|}
\hline Máquinas e ferramentas utilizadas & $\begin{array}{l}\text { Tempo de preparação (caso exista uma } \\
\text { preparação para o uso) (em minutos) }\end{array}$ & $\begin{array}{l}\text { Tempo usado no equipamento para o } \\
\text { processamento (em minutos) }\end{array}$ \\
\hline 1. $\quad$ Serviço terceirizado & - & - \\
\hline 2. Tanque de ácido & $10 \mathrm{~min}$ & 2. $30 \mathrm{~min}$ por lote \\
\hline 3. $\quad$ Material de limpeza e pincel & - & 3. $30 \mathrm{~min}$ por lote \\
\hline 4. $\quad$ Furadeira vertical, broca & $5 \mathrm{~min}$ & 4. $120 \mathrm{~min}$ por lote \\
\hline 5. $\quad$ Pinças, ferro de solda, Kit SMD & $10 \mathrm{~min}$ & 5. $15 \mathrm{~min}$ \\
\hline 5. $\quad$ Pinças, ferro de solda, Kit SMD & $10 \mathrm{~min}$ & 5. $15 \mathrm{~min}$ \\
\hline 7. Ferro de solda & - & 7. 2 min por PCI \\
\hline 8. 2 Furadeiras verticais, 2 brocas & $10 \mathrm{~min}$ & 8. 1 min por furadeira por $\mathrm{PCI}$ \\
\hline $\begin{array}{l}\text { 9. Alicate de corte, ferro de solda, } \\
\text { gabarito, fonte de alimentação, } \\
\text { miliamperímetro e voltímetro. }\end{array}$ & - & 9. 1 min por luminária \\
\hline $\begin{array}{l}\text { 10. Calibragem do compressor e } \\
\text { carregamento inicial. Batedeira grande } \\
\text { para homogeneização. Dosimetro para } \\
\text { catalisador. Batedeira pequena. Panela de } \\
\text { mistura e aplicação pressurizada . }\end{array}$ & $10 \min +20 \min +5 \min +3 \min +20 \min$ & 10. 2,5 min por luminária \\
\hline 11. Pinça ou gabarito de limpeza & - & 11. 0,5 min por luminária \\
\hline $\begin{array}{l}\text { 12. Fonte de alimentação, voltímetro e } \\
\text { amperímetro }\end{array}$ & - & 12. 1 min por luminária \\
\hline
\end{tabular}

Fonte: Pesquisa de campo (2013)

Estabelecido o levantamento de dados sobre o produto, a quantidade, o roteiro, os serviços de suporte e o tempo de produção, tem-se o checklist para iniciar as etapas do planejamento sistemático de layout propriamente dito.

\subsection{Etapa de localização}

Estão inclusos nesta etapa os estudos de marketing para estabelecer as potencialidades do mercado local, acesso aos fornecedores bem como análise dos modais de transporte (MARTINS \& LAUGENI, 2005).

A empresa foco da presente pesquisa já está estabelecida há mais de 20 (vinte) anos em uma área geograficamente privilegiada (Polo Naval do Estado do Rio Grande do Sul).

Por estar em um distrito industrial, desfruta de vantagens fiscais e outros incentivos governamentais.

Suas instalações físicas totalizam $1.200 \mathrm{~m}^{2}$ (mil e duzentos), sendo que $350 \mathrm{~m}^{2}$ (trezentos e cinquenta) encontram-se disponíveis para ampliação da planta produtiva.

Dessa forma, considera-se que a empresa está geograficamente posicionada de uma forma estratégica, não havendo necessidade de demandar um estudo sobre novas alternativas e possibilidades para a instalação da planta de produção.

\subsection{Etapa de layout geral}

A etapa de layout geral consiste, basicamente, no levantamento de dados do processso produtivo que sirvam de fundamentação para a proposição de um novo layout. Em uma intervenção à realidade organizacional, os pesquisadores: i) determinam a análise do fluxo de materiais; ii) 
verificam as inter-relações de atividades, iii) procedem à verificação do espaço disponível e necessário, e iv) elaboram o diagrama de relações entre áreas.

\section{I) análise do fluxo de materiais}

Para determinar a análise do fluxo de materiais da empresa foi utilizada a matriz de movimentação de materiais.

A matriz de movimentações de materiais indica quais os processos técnicos utilizados e as operações envolvidas na produção. Mensurando as quantidades que serão fabricadas torna-se possível compreender como se dará a circulação e sua intensidade. Esta matriz pode ser obtida elaborando-se uma tabela matricial (MATOS, MARIANO e ALMEIDA, 2010).

No Quadro 4, pode-se observar a matriz de movimentação para produção das luminárias de led. Ela apresenta as quantidades de materiais que são movimentados de um processamento para o outro. Neste caso, por exemplo, 1000 peças são movimentadas de "serigrafia PCI" para "corrosão PCI" e, na sequência, 1000 da "corrosão PCI” para "verniz PCI".

No Quadro 4, onde há intersecção do mesmo processo, a matriz apresenta a célula hachurada, já onde não há movimentação, ela apresenta o valor zero.

\begin{tabular}{|c|c|c|c|c|c|c|c|c|c|c|c|c|c|c|c|c|c|}
\hline \multirow[b]{2}{*}{$\begin{array}{l}\text { FLUXO DE MOVIMENTAÇÃO } \\
\text { PRODUTO LUMINÁRIA DE LED }\end{array}$} & \multicolumn{17}{|c|}{ PARA: } \\
\hline &  & $\begin{array}{l}0 \\
0 \\
0 \\
0 \\
1 \\
0 \\
0 \\
0 \\
0 \\
0 \\
0 \\
0\end{array}$ & $\begin{array}{l}\vec{U} \\
\Delta \\
N \\
Z \\
\frac{a}{y} \\
>\end{array}$ & 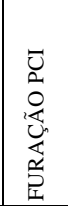 & 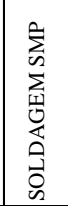 & 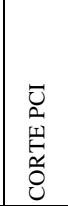 &  &  & 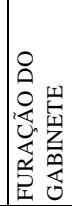 & 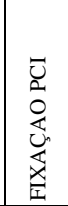 &  &  & 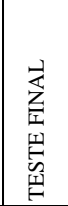 & 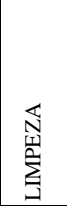 & 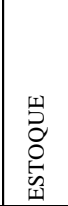 & 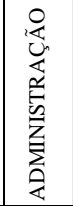 &  \\
\hline SERIGRAFIA PCI & & 1000 & 0 & 0 & 0 & 0 & 0 & 0 & 0 & 0 & 0 & 0 & 0 & 0 & 0 & 0 & 0 \\
\hline CORROSÃO PCI & 0 & & 1000 & 0 & 0 & 0 & 0 & 0 & 0 & 0 & 0 & 0 & 0 & 0 & 0 & 0 & 0 \\
\hline VERNIZ PCI & 0 & 0 & & 1000 & 0 & 0 & 0 & 0 & 0 & 0 & 0 & 0 & 0 & 0 & 0 & 0 & 0 \\
\hline FURAÇÃO PCI & 0 & 0 & 0 & & 1000 & 0 & 0 & 0 & 0 & 0 & 0 & 0 & 0 & 0 & 0 & 0 & 0 \\
\hline SOLDAGEM SMP & 0 & 0 & 0 & 0 &  & 1000 & 0 & 0 & 0 & 0 & 0 & 0 & 0 & 0 & 0 & 0 & 0 \\
\hline CORTE PCI & 0 & 0 & 0 & 0 & 0 & & 1000 & 0 & 0 & 0 & 0 & 0 & 0 & 0 & 0 & 0 & 0 \\
\hline SOLDAGEM LEDS & 0 & 0 & 0 & 0 & 0 & 0 & & 1000 & 0 & 0 & 0 & 0 & 0 & 0 & 0 & 0 & 0 \\
\hline CORTE GABINETE & 0 & 0 & 0 & 0 & 0 & 0 & 0 & & 1000 & 0 & 0 & 0 & 0 & 0 & 0 & 0 & 0 \\
\hline FURAÇÃO DO GABINETE & 0 & 0 & 0 & 0 & 0 & 0 & 0 & 0 & & 1000 & 0 & 0 & 0 & 0 & 0 & 0 & 0 \\
\hline FIXAÇAO PCI & 0 & 0 & 0 & 0 & 0 & 0 & 0 & 0 & 0 & & 1000 & 0 & 0 & 0 & 0 & 0 & 0 \\
\hline TESTE & 0 & 0 & 0 & 0 & 0 & 0 & 0 & 0 & 0 & 0 & & 1000 & 0 & 0 & 0 & 0 & 0 \\
\hline COLOCAÇÃO BORRACHA & 0 & 0 & 0 & 0 & 0 & 0 & 0 & 0 & 0 & 0 & 0 & & 1000 & 0 & 0 & 0 & 0 \\
\hline LIMPEZA & 0 & 0 & 0 & 0 & 0 & 0 & 0 & 0 & 0 & 0 & 0 & 0 & & 1000 & 0 & 0 & 0 \\
\hline TESTE FINAL & 0 & 0 & 0 & 0 & 0 & 0 & 0 & 0 & 0 & 0 & 0 & 0 & 0 & & 1000 & 0 & 0 \\
\hline ESTOQUE & 0 & 0 & 0 & 0 & 0 & 0 & 0 & 0 & 0 & 0 & 0 & 0 & 0 & 0 & & 1000 & 0 \\
\hline ADMINISTRAÇÃO & 0 & 0 & 0 & 0 & 0 & 0 & 0 & 0 & 0 & 0 & 0 & 0 & 0 & 0 & 0 & & 1000 \\
\hline RECEBIMENTO \EXPEDIÇÃO & 0 & 0 & 0 & 0 & 0 & 0 & 0 & 0 & 0 & 0 & 0 & 0 & 0 & 0 & 0 & 0 & \\
\hline
\end{tabular}

\section{II) análise das inter-relações de atividades}

A análise das inter-relações de atividades do processo de produção das luminárias foi realizada tendo como base a carta de interligações de atividades. Esta articula as atividades do processo e a sequência de suas atividades atribuindo importância à proximidade entre atividades e estabelecendo a motivação (lógica ou não) desta. 
$\mathrm{Na}$ carta de interligações de atividades a importância da proximidade das atividades é dada pela seguinte escala semântica: (A) - absolutamente necessária, (E) - muito importante, (I) importante, $(\mathrm{O})$ - pouco importante, $(\mathrm{U})$ - desprezível e, $(\mathrm{X})$ - indesejável. Quanto à razão da proximidade entre as atividades do processo, a carta de interligações classifica em: (1) - funções subsequentes, (2) - compartilham mesma área e, (3) - sem razão (não se verifica lógica) alguma.

Com base nas informações levantadas na empresa objeto do estudo de caso, os pesquisadores elaboraram a carta de interligações para o processo de fabricação de luminárias de led, conforme ilustra a Figura 2. Ela elenca as dezessete atividades do processo e estabelece o relacionamento dessas em função da proximidade e razão.

Figura 2 - Carta de interligações para o processo de fabricação de luminárias de led

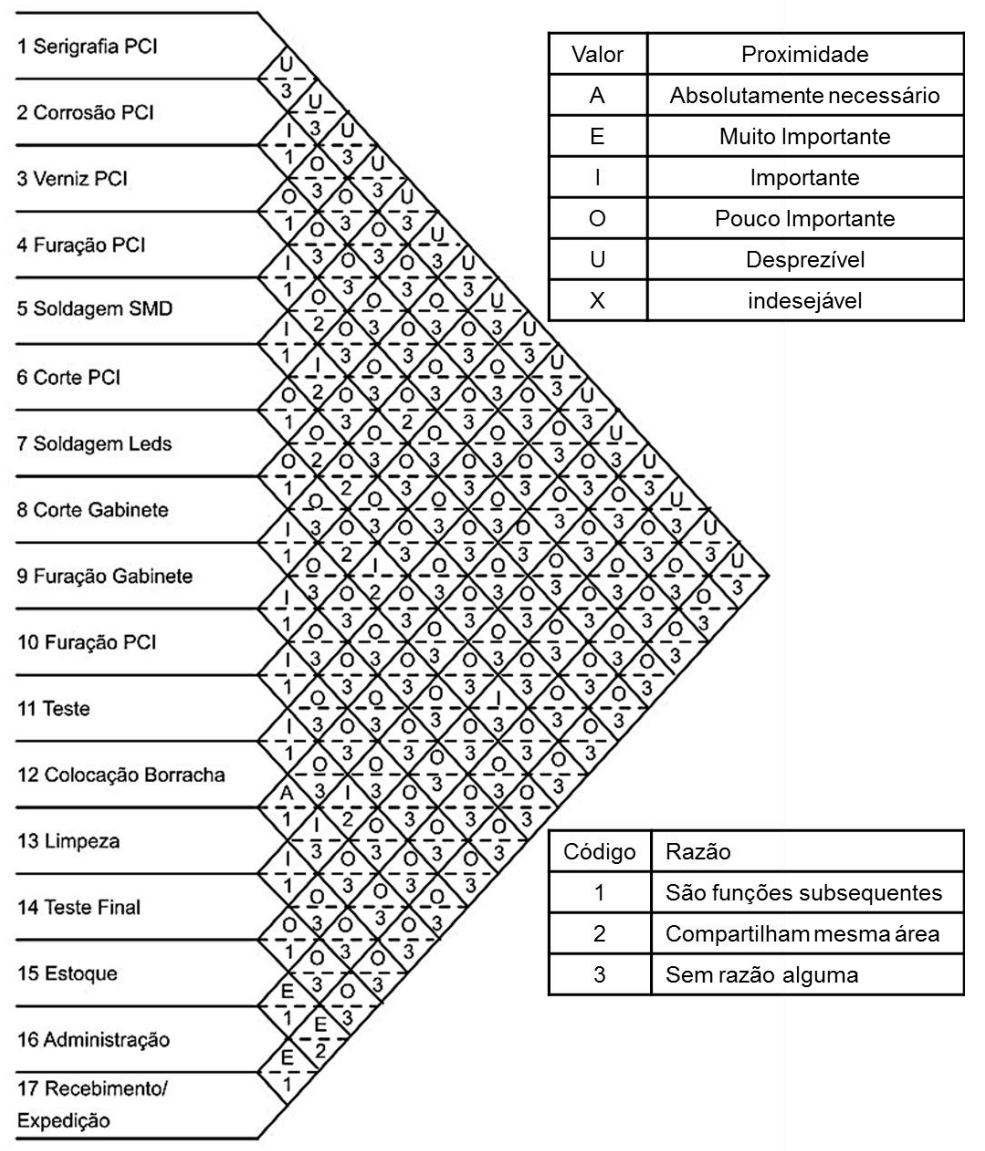

Fonte: Pesquisa de campo (2013)

Por meio da Figura 2 é possível verificar, por exemplo, que a proximidade entre as atividades 1 - serigrafia e PCI e (4) furação PCI é classificada como (E) - muito importante. Isso se justifica pelo fato de tais atividades contemplarem a razão (1) - funções subsequentes, o que facilita o processo de fabricação.

Nota-se, ainda, que as atividades 3 - verniz PCI e 4 - furação PCI são classificadas quanto à proximidade como (I) - importante e quanto à razão que justifica essa proximidade como (1) funções subsequentes. 


\section{III) verificação do espaço disponível e necessário}

A verificação do espaço disponível e necessário se dá por meio do levantamento das dimensões ocupadas (área, volume, comprimento, largura), pelos instrumentos, máquinas e ferramentas empregados no processo de produção.

Nesta etapa os pesquisadores também levaram em conta aspectos como a necessidade de energia (voltagem e amperagem), ar comprimido, acesso a pontos de água e tubulações específicas, drenos etc. O Quadro 5 ilustra o levantamento de espaço para o caso em questão.

\begin{tabular}{|c|c|c|c|c|c|c|c|c|c|c|c|c|c|c|c|c|c|c|}
\hline \multicolumn{19}{|c|}{ Quadro 5 - Levantamento de espaço } \\
\hline Nome e/ou descriçao &  & 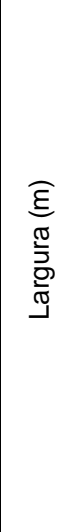 &  & 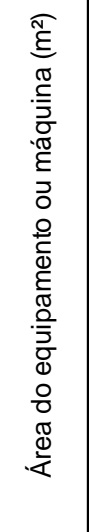 &  & 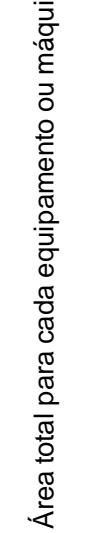 & $\mid \begin{array}{l}\dot{X} \\
0 \\
0 \\
0 \\
\underline{0}\end{array}$ & $\begin{array}{l}0 \\
0 \\
\dot{\mathbb{S}} \\
\stackrel{N}{N}\end{array}$ & 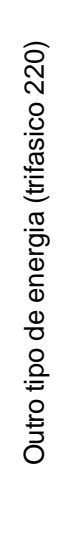 & 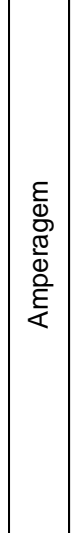 & 㞼 & 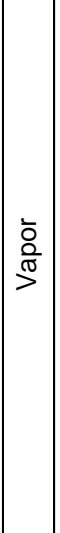 & $\mid \begin{array}{l}0 \\
\stackrel{0}{\Phi} \\
\stackrel{\Phi}{0} \\
\end{array}$ & 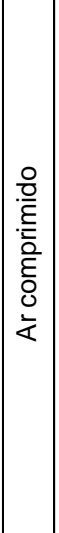 & 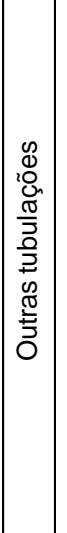 & 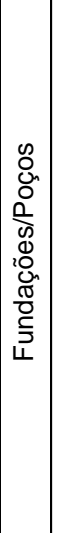 & 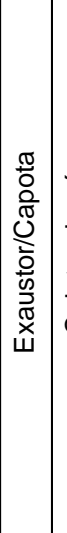 &  \\
\hline TANQUE DE ÁCIDO & 0,60 & 0,30 & 0,40 & 0,18 & 6,00 & 6,00 & 4 & 4 & & & $\mathrm{x}$ & & $\mathrm{x}$ & & & & & \\
\hline SERRA CIRCULAR & 0,80 & 0,50 & 0,80 & 0,40 & 6,00 & 6,00 & 7 & $\mathrm{x}$ & & & & & & & & & & \\
\hline FURADEIRA VERTICAL & 0,40 & 0,40 & 1,80 & \begin{tabular}{|l|l|}
0,16 \\
\end{tabular} & 2,00 & 2,00 & $Z$ & $\mathrm{x}$ & & & $\triangle$ & & & & & & & \\
\hline ESTAÇÃO DE SOLDA SMD & 0,20 & 0,20 & 0,20 & \begin{tabular}{|l|}
0,04 \\
\end{tabular} & 1,00 & 1,00 & $\mathrm{x}$ & & & & $\mathrm{x}$ & & & & & 7 & & $Z$ \\
\hline FURADEIRA VERTICAL & 0,80 & 0,50 & 1,90 & 0,40 & 2,00 & 2,00 & 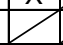 & 7 & $\mathrm{x}$ & & & & & & & & & \\
\hline \multirow{2}{*}{\multicolumn{19}{|c|}{$\begin{array}{c}\text { FONTE DE ALIMENTAÇ̃̃̃O } \\
\text { MILIAMPERIIMETRO }\end{array}$}} \\
\hline & & & & & & & & & & & & & & & & & & \\
\hline VOLTÍMETRO & 1,00 & 0,80 & 0,80 & 0,80 & 2,00 & 2,00 & & $\mathrm{x}$ & & & & & & & & $\zeta$ & & $\angle$ \\
\hline SERRA CIRCULAR GRANDE & 2,00 & 0,80 & 0,80 & \begin{tabular}{|l|}
1,60 \\
\end{tabular} & 8,00 & 8,00 & & & $\mathrm{X}$ & $15 \mathrm{~A}$ & $Z$ & & & & & & & $x$ \\
\hline POLICORTE & 0,60 & 6,00 & 1,80 & 3,60 & 8,00 & 8,00 & & & $\mathrm{X}$ & $20 \mathrm{~A}$ & & & $\mathrm{X}$ & & & & & $\mathrm{x}$ \\
\hline BATEDEIRA PEQUENA & & & & & & & $\mathrm{X}$ & & & & $\mathrm{x}$ & & $\mathrm{x}$ & & & & & \\
\hline BATEDEIRA GRANDE & & & & & & & & & & & $\mathrm{X}$ & & $\mathrm{x}$ & & & & & \\
\hline ANELA DE MISTURA/APLICAÇÃ & 0,30 & 0,30 & 0,80 & 0,09 & 2,00 & 2,00 & & & & & & & & $\mathrm{X}$ & & & & \\
\hline COMPRESSOR & 0,90 & 0,50 & 0,10 & 0,45 & 1,00 & 1,00 & & $\mathrm{x}$ & & $4 \mathrm{~A}$ & & & & & & & & \\
\hline
\end{tabular}

Pela análise de espaço do Quadro 5 é possível verificar que o somatório de todos os itens da coluna "Área total para cada equipamento ou máquina" resulta na necessidade de $38 \mathrm{~m}^{2}$ para o atual processo de produção das luminárias. Como o espaço disponível é de $100 \mathrm{~m}^{2}$, isto significa que há uma área de $62 \mathrm{~m}^{2}$ que pode ser utilizada no novo arranjo do layout produtivo da fábrica.

\section{IV) diagrama de relação entre as áreas}

Nesta etapa, após algumas intervenções junto à empresa, os pesquisadores observaram que as 17 atividades realizadas ao longo do processo de produção da luminária de led poderiam ser agregadas em quatro áreas. Além disso, determinaram o relacionamento entre elas. 
Foram identificadas as áreas de armazenagem de matéria-prima; corte e furação; montagem, soldagem e inspeção; e, acabamento (corrosão, verniz, colocação de borracha, limpeza e armazenamento do produto acabado).

Após, seguindo a sugestão de Muther (1978), foi adotada uma simbologia representativa, onde cada área corresponde a uma figura de cor diferenciada, conforme Figura 3:

Figura 3 - Representação das áreas do processo

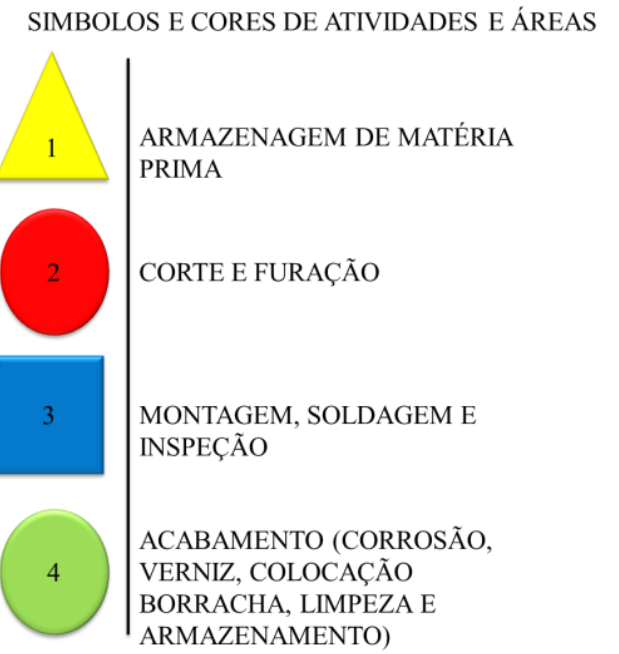

Fonte: Autoria própria (2013)

Outra orientação, diz respeito às linhas de importância entre os relacionamentos das áreas, cuja simbologia é evidenciada na Figura 4:

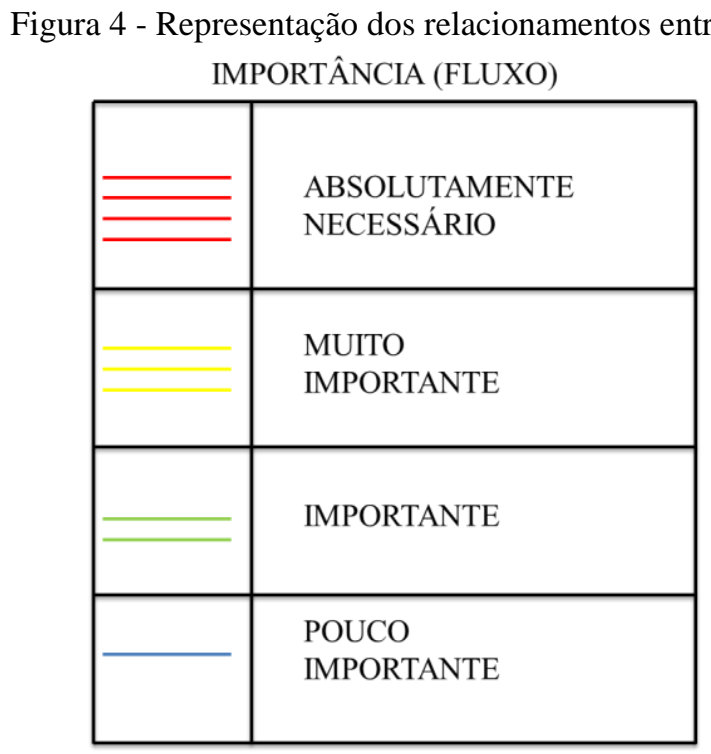

Fonte: Autoria própria (2013)

Com estas informações foi possível proceder à elaboração do esquema representado pela Figura 5, que elucida a situação atual dos relacionamentos entre as áreas do processo de produção da empresa objeto de estudo. 




Fonte: Pesquisa de campo (2013)

A Figura 5 demonstra as áreas do processo de produção, seus relacionamentos e o grau de importância entre eles. Nela é possível observar que o relacionamento com maior grau de importância em todo o ciclo ocorre entre as áreas 2 e 3, respectivamente, a área de corte e furação com a área de montagem, soldagem e inspeção. Como estão posicionadas, uma ao lado da outra, pode-se inferir que o arranjo atual entre essas duas áreas é, portanto, coerente.

Em outra análise, as áreas 1 - armazenagem de matéria-prima e 4 - acabamento, apesar de possuírem um nível de relacionamento classificado como importante estão nos extremos opostos do arranjo físico atual da produção. Como o objetivo da célula produtiva é a otimização do processo, o arranjo entre 1 e 4 não é o mais adequado.

A mesma conclusão pode ser estendida ao arranjo entre as áreas 1 e 3, bem como o arranjo entre as áreas 2 e 4 . Em ambos, não foi observado o critério de proximidade entre funções subsequentes ou afins do processo produtivo.

Tendo sido concluído o levantamento do fluxo de atividades, elaborada a carta de interligações, procedido o exame do espaço disponível e necessário e estabelecido o diagrama de relacionamentos entre as áreas do processo, conclui-se a etapa de verificação do layout geral proposta pela metodologia SLP.

\subsection{Etapa de layout detalhado}

$\mathrm{Na}$ etapa de layout detalhado cabe aos pesquisadores, fazendo uso dos dados levantados nas etapas anteriores do SLP, propor alternativas de arranjo físico que objetivem a otimização do espaço e do fluxo de atividades do processo produtivo.

Nesse sentido, a Figura 6 traz o modelo A, um rearranjo das células que proporciona menor desgaste para o processo, pois aproxima áreas correlatas e de intenso fluxo. É possível verificar que as áreas que geram maior trânsito de materiais em processamento estão alocadas o mais próximo possível. Isso fica claro ao observar as linhas paralelas de cor vermelha e amarela, já as áreas com menor fluxo estão representadas pelas linhas verdes e azuis. 
Figura 6 - Fluxo de material em processamento entre as áreas - modelo A

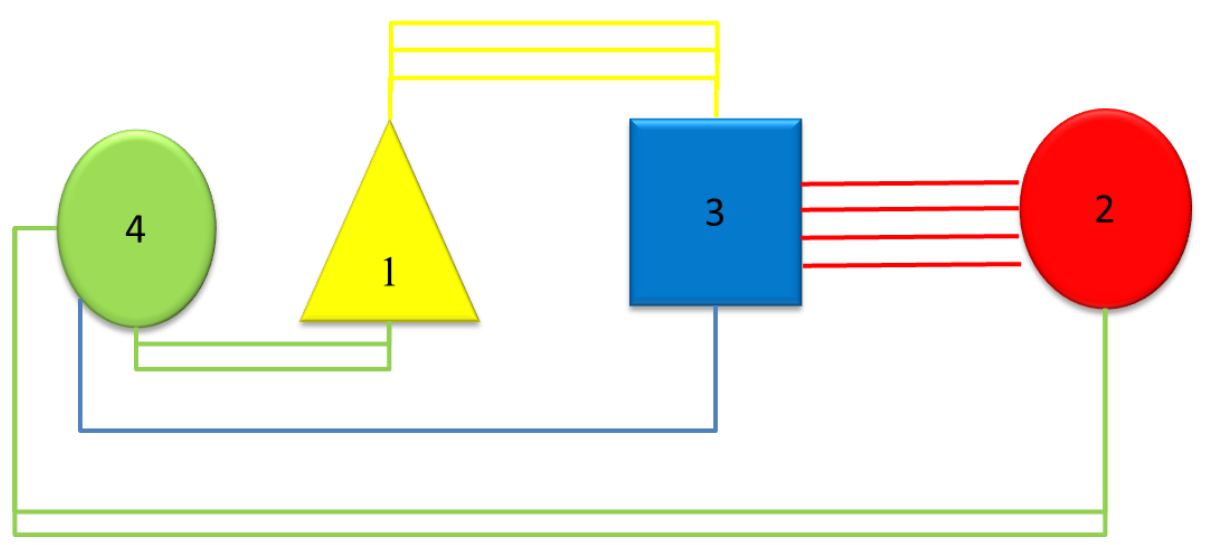

Fonte: Pesquisa de campo (2013)

Como é necessário avaliar mais do que simplesmente os fluxos, foi proposto outro arranjo (modelo B) que possui o mesmo proposito em outro modelo. De acordo com a proposta do SLP, é imprescindível indicar mais de um layout para que existam parâmetros de comparação e escolha, pois nem sempre o mais eficiente é o mais viável para aplicação na empresa. Desta forma, foram elaborados dois modelos que melhoram o fluxo de materiais em processamento e fundamentam-se nas necessidades evidencias de proximidade, bem como suas razões. A Figura 7 ilustra esta proposta.

Figura 7. Fluxo de material em processamento entre as áreas - modelo B

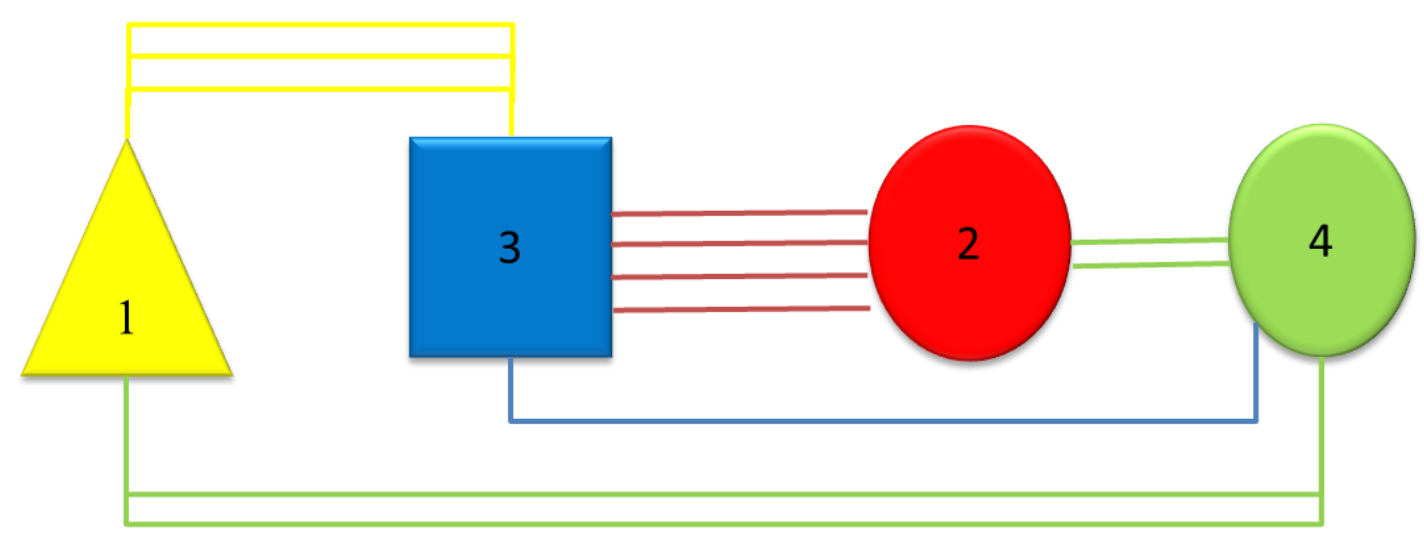

Fonte: Pesquisa de campo (2013)

Ainda na Figura 7 verifica-se que são respeitados os fluxos, onde as áreas de maior fluxo permanecem próximas e as de menor fluxo e importância relativa são alocadas de forma que atendam as necessidades da fábrica e gerem menos retrabalho.

Com a intenção de exemplificar com maior fidelidade o layout da empresa, foi elaborada a Figura 8, representado as áreas com seus respectivos maquinários, respeitando a fábrica original. 
Figura 8 - Levantamento do ambiente



Fonte: Pesquisa de campo (2013)

Com estas informações foi possível separar as áreas em células produtivas, conforme a Figura 9. Nela é destacada cada área com seu dimensionamento de acordo com o trabalho que será realizado, o maquinário utilizado e as condições de infraestrutura necessária.

Figura 9 - Levantamento das áreas (células)

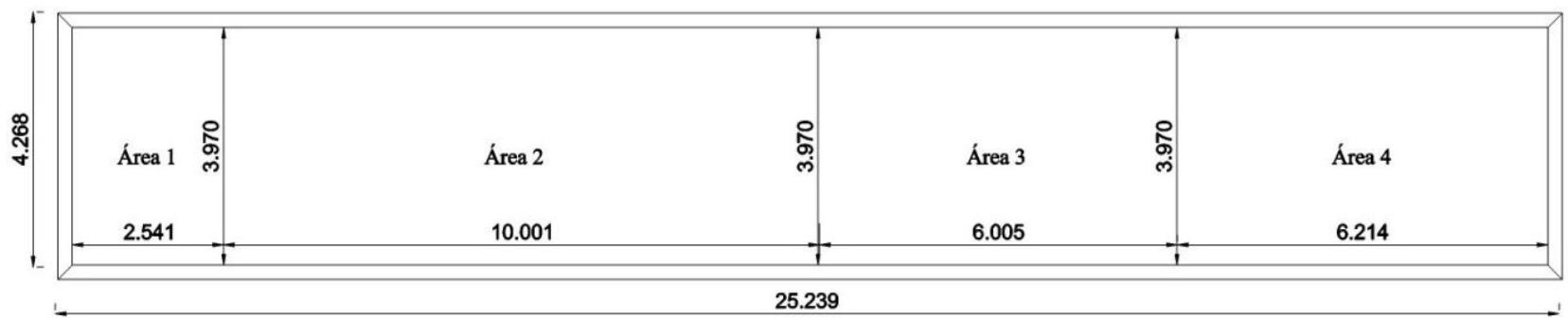

Fonte: Pesquisa de campo (2013)

Foram estabelecidas quatro células onde o modelo A é representado, conforme a Figura 10. Esta figura tem o proposito de elucidar realisticamente como este modelo pode ser implantado na empresa.

Figura 10 - Alternativa de acordo com o modelo A

Projeto Geral em prédio existente alternativa $\mathrm{A}$



Fonte: Pesquisa de campo (2013)

Já na Figura 11, está representado o modelo B, que segue os mesmos princípios do modelo anterior, porém arranjado de outra maneira, proporcionando a comparação e escolha do mais adequado à realidade de empresa objeto de estudo. 
Figura 11 - Alternativa de acordo com o modelo B

Projeto Geral em Prédio Existente Alternativa B

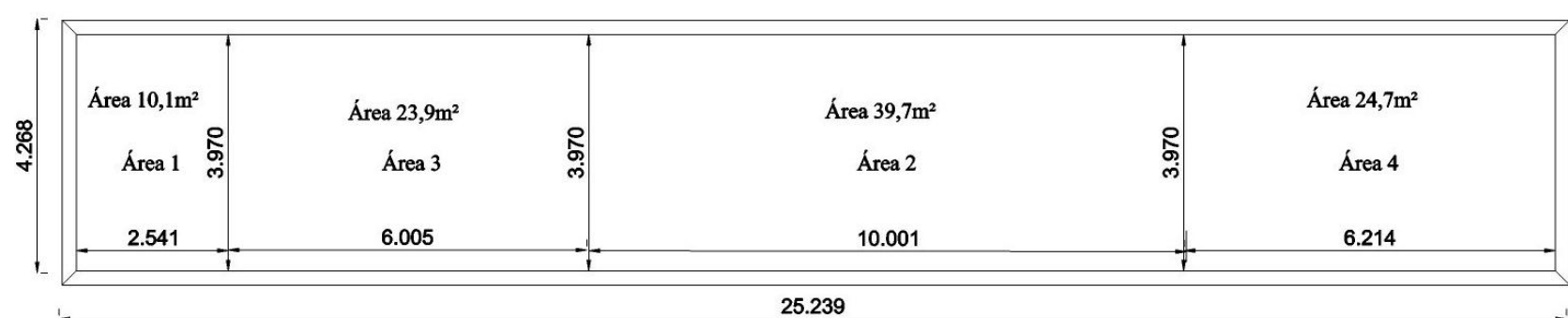

Fonte: Pesquisa de campo (2013)

Com estas duas alternativas é possível a avaliação para escolha da alternativa mais adequada de layout para a fábrica, levando em consideração a produtividade necessária, o fluxo de materiais, a economicidade de movimentos, a facilidade de supervisão e o custo de alteração nas instalações.

\subsection{Etapa de implantação}

Nesta etapa os pesquisadores realizaram entrevistas com os responsáveis pela produção da empresa. Os dois modelos de layout propostos (A e B) foram apresentados aos gerentes da produção, para que esses apontassem o arranjo físico mais coerente e que seria de fato implantado na célula fabril de luminárias de led.

Para realizar a avaliação foi utilizada a legenda de acordo com o Quadro 6, que estabelece a escala para análise do grau de perfeição que o modelo proporciona.

Quadro 6 - Escala de análise do grau de perfeição de
\begin{tabular}{|c|c|c|}
\hline Legenda & Valor & Significado \\
\hline A & 4 & Quase perfeito \\
\hline E & 3 & Muito bom \\
\hline I & 2 & Bom \\
\hline O & 1 & Razoável \\
\hline U & 0 & Ruim \\
\hline
\end{tabular}
Fonte: Autoria própria (2013)

A partir da utilização do grau de perfeição e do peso atribuído para cada fator, foi possível realizar a média ponderada de cada modelo, conforme exposto no Quadro 7. O julgamento foi feito multiplicando-se o valor conferido à legenda pelo peso atribuído ao fator.

Quadro 7 - Avaliação das propostas de layout

\begin{tabular}{|l|r|r|l|l||}
\hline & \multicolumn{3}{|c|}{ AVALIAÇÃO E AVALIAÇÃO PONDERADA } \\
\hline FATOR/CONSIDERAÇAO & PESO & ATUAL & MODELO A & MODELO B \\
\hline PRODUTIVIDADE & 5 & A/20 & A/20 & A/20 \\
\hline FLUXO DE MATERIAIS E ECONOMICIDADE DE MOVIMENTOS & 5 & O/5 & A/20 & A/20 \\
\hline FACILIDADE DE SUPERVISÃO & 3 & A/12 & E/9 & A/12 \\
\hline CUSTO (ALTERAÇÃO DE INSTALAÇÕES) & 4 & E/12 & A/16 & A/16 \\
\hline TOTAIS & & 49 & 65 & 68 \\
\hline \hline
\end{tabular}

Fonte: Pesquisa de campo (2013)

Em consonância com a metodologia proposta foi possível estabelecer, que para a empresa objeto de estudo, o modelo que melhor atende sua necessidade e lhe proporciona melhoria no 
processo produtivo é o modelo $\mathrm{B}$, pois obteve a maior nota. Este modelo acata os requisitos propostos no SLP e sua implantação é exequível pela fabrica em questão.

\section{Considerações finais}

O planejamento do layout vem sendo cada vez mais disseminado como forma de alcançar os objetivos da empresa com maior eficiência, o trabalho realizado demonstrou que as micro empresas podem utilizar esta metodologia, pois a mesma, possui baixo custo de aplicação e fornece resultados praticáveis dentro de sua realidade. Outro aspecto que se pôde verificar é o uso da metodologia no caso de células produtivas que, conforme levantado na revisão, era um modelo não contemplado na sua formulação.

Com o aumento destas empresas no cenário atual tornou-se cada vez mais importante que as mesmas preparem-se para atender suas demandas com o menor custo possível. Com o uso desta metodologia foi possível identificar áreas com grande fluxo de materiais em processamento, sendo assim, melhorando consideravelmente o tempo gasto com deslocamentos dentro da fábrica. Fator este que além de tornar a produção mais rápida, faz com que a capacidade produtiva da empresa aumentasse, ela pode produzir mais em menos tempo e com menos custo.

O processo de aplicação da metodologia SLP iniciou com o levantamento das características dos espaços da fábrica, o que é essencial para determinar como será sua instalação, como se dá a movimentação dos materiais em processamento, identificando as áreas correlatas e sequenciais.

Outro fator a destacar foi a possibilidade de verificar quais as operações mais recorrentes e que, por este motivo, mais impactam na produtividade. Também se averiguou os espaços necessários para alocação de máquinas e equipamentos, bem como o tamanho do posto de trabalho, item essencial para o cálculo da célula de produção.

Pôde-se levantar a necessidade de proximidade entre as áreas com base na sequencia das funções ou atividades, compartilhamento de espaços e conveniência para realização do processamento.

Agregado a este elemento ficou evidenciado o quanto cada fator é importante dentro da fábrica, com o intuito de tornar o trabalho exequível. Também foi possível identificar e organizar as áreas em células de produção, o que enriquece o trabalho e torna o fluxo mais fluente resultando em maior flexibilidade, velocidade e eficiência. Estes são importantes resultados para a empresa objeto de estudo, pois a mesma pretende aumentar sua linha de produtos e, desta forma, a intensidade da produção.

Acrescenta-se o fluxo de materiais em processamento, resultando em uma melhor visualização do aproveitamento do espaço da fábrica. 
Com o arrolamento destas informações, tornou-se possível elaborar um modelo representativo de como a fábrica funciona e propor duas alternativas para melhor a produção, tornando-a mais eficaz. Adicionaram-se a estes modelos os espaços relativos às células de produção, possibilitando a formulação de um esboço da planta elucidando o layout.

A partir destas informações, recolhidas e configuradas de forma estruturada, conforme o modelo do SLP, a avaliação dos modelos foi realizável, da mesma maneira a averiguação da mais eficaz de acordo com as características da empresa estudada, bem como suas limitações inerentes ao porte e recursos disponíveis.

O presente estudo também evidenciou que o layout utilizado pela empresa poderia ser melhorado consideravelmente, a fim de proporcionar a capacidade produtiva desejada e reduzir seu tempo de processamento e espera, da mesma forma que torna a produção mais eficaz, gera uma capacidade produtiva maior que vai ao encontro da satisfação da necessidade emergente.

Desta forma, foi possível encontrar um modelo de layout eficaz e realístico, que contempla fatores objetivos, como os fluxos de materiais e, subjetivos como avaliação de importância relativa.

Conclui-se, portanto, que a metodologia SLP auxilia no processo de elaboração e escolha de alternativas de layout produtivo para MPE's, com arranjo produtivo em células, mostrando-se capaz de alavancar melhorias que apoiam a empresa a produzir de forma mais eficaz, minimizando o esforço na produção e consecutivamente, impactando em diminuição dos custos e maior produtividade.

\section{Abstract}

This paper describes the application of Systematic Layout Planning (SLP) for generates a layout template to marine lights manufacturer, located in the Rio Grande Naval hub, Brazil. Through the use of theoretical setup that instrumentalizes SLP, procedures were carried out survey work environment, the movement of materials in processing of frequently used operations and their impact on production. In addition, there is the space needed for the job, as well as the need for proximity. It was possible to highlight the productive cells and check the flow between them, resulting in the development of two models of layout achievable, taking into account the limitations of the organization's facilities. As a result, we performed a thorough evaluation of the models and selected the one best suited to the case study. These assessments allowed the proposition of applying a layout template based SLP for the company.

Key-words: layout design; production cell; Systematic Layout Planning.

\section{Referências}

ANTUNES, J.; ALVAREZ, R.; PELLEGRIN, I.; KLIPPEL, M.. Sistemas de produção: conceitos e práticas para projeto e gestão da produção enxuta. Porto Alegre: Bookman, 2008.

BILBY, B. A.; CORRÊA, B. S.; BAHIA, P. Q. Avaliação e otimização da logística interna de materiais em uma organização social com atividade produtiva vertical: um estudo de caso. São Carlos: ENEGEP, 2010. 
CORRÊA, H. L.; CORRÊA, C. A. Administração de produção e operações, 2. ed., São Paulo: Atlas, 2010.

COSTA, A. J. Otimização do layout de produção de um processo de pintura de ônibus. Porto Alegre: Dissertação de Mestrado PPGEP - UFRGS, 2004.

DAVIS, M. M.; AQUILANO, N. J.;CHASE, R. B.. Fundamentos da Administração da produção, 3 ed., Porto Alegre: Bookman, 2001.

ELIAS, S. J. B.; REBOUÇAS, T. V.; XEREX, J. C. Implantação da Produção Enxuta em uma Indústria de Transformadores: o Caso CEMEC. Florianópolis: ENEGEP, 2004.

EMERIQUE, C. C. T.; CARDOSO, J. R. de L.; FREITAS, F. F. T. Planejamento Sistemático de Layout: aplicação em uma empresa do ramo automobilístico. Belo Horizonte: ENEGEP, 2011.

FITZSIMMONS, J. A.; FITZSIMMONS, M. J. Administração de serviços: operações, estratégia e tecnologia da informação. 6.ed. Porto Alegre: Bookman, 2010

GONÇALVES FILHO, E. V.. Arranjo físico de fábrica: um modelo para o processo de projeto e um algoritmo genérico para a formação de células de produção. São Carlos: Tese.de Doutorado EESC - USP, 2001.

JUNIOR, J. A. S.; ANDRADE, M. H. S.; CARMO, B. B. T.; SANTIAGO, K. J. ALBERTIN, M. R. Identificação do layout adequado em uma empresa de tecnologia eletrônica. Revista Eletrônica Sistemas \& Gestão, p. 1-22, 2012.

MARTINS, P.; LAUGENI, F. Administração da produção. São Paulo: Saraiva, 2005.

LUSTOSA, L; MESQUITA, M.A.; QUELHAS, O.; OLIVEIRA, R. J. Planejamento e Controle da Produção. Rio de Janeiro: Campus Elsevier, 2008.

MARUJO, L. G.; CARVALHO, D.; LEITÃO, M. N. Otimização de Layout utilizando-se o SLP combinado com Teoria das Filas: um estudo de caso em uma oficina de rodas e freios de aeronaves. Ponta Grossa: Revista Gestão Industrial, v. 06, n. 04: p. 93-109, 2010. crossref

MATOS, A. P.; MARIANO, A.; ALMEIDA, B.; Layout: Gestão das operações. Bookman, 2010.

MOREIRA, D. A. Administração da produção e operações. 2. ed.,São Paulo: Atlas, 1993.

MUTHER. R. Planejamento do layout: sistema SLP. São Paulo: Edgar Blucher, 1978.

PRATA, A. B.. Arranjo físico celular: uma abordagem conceitual. Fortaleza: Monografia de conclusão do curso de especialização em engenharia da produção Universidade Federal do Ceará, 2002.

ROCHA, F. B. A.; CAMPOS, M. C.;PACHECO, N. O.; SILVEIRA, R. R.; FALANI, S. Y. A.. Estudo do layout através do SLP: uma proposta com validação pelo método score para uma fábrica de polpa de frutas. Belo Horizonte: ENEGEP, 2011.

ROSI, V. R.; LOUREIRO, A. B.; FERREIRA FILHO, J. C.. Aplicação do sistema SLP em uma indústria de móveis seriados. São Carlos: ENEGEP SP, 2010.

SANTOS, L. C.; GOHR, C. F.; LAITANO, J. C. A. Planejamento Sistemático de Layout: adaptação e aplicação em operações de serviços. Ponta Grossa: Revista Gestão Industrial, v. 08, n. 01: p. 01-21, 2012.

SEBRAE. Anuário do trabalho na micro e pequena empresa. Brasília, DIEESE, 2012.

SILVA, E. L.; MENEZES, E. M.. Metodologia da Pesquisa e Elaboração de Dissertação. 3. ed., Florianópolis: PPGEP - UFSC, 2001.

SILVA, M. G.; MOREIRA, B. B. Aplicação da metodologia SLP na reformulação do layout de uma microempresa do setor moveleiro. Salvador: ENEGEP, 2009.

SLACK, N. JOHNSTON, R.; CHAMBERS, S.. Administração da Produção, 2. ed., São Paulo: Atlas, 2009.

TOMPKINS, J. A.; WHITE, J. A.; BOZER, Y A. Facilities planning. New York: John Wiley \& Sons, 1996. 
TORTORELLA, G. L.; FOGLIATTO, F. S. Planejamento Sistemático de layout com apoio de análise de decisão multicritério. Porto Alegre: Produto e Produção, v. 18, n. 3, p. 609-624, 2008. crossref

YANG, T.; SU, C.; HSU, Y. Systematic Layout Planning: a study on semiconductor wafer fabrication facilities. International Journal of Production Management, v. 20, p. 1359-1371, 2000. crossref

\section{Dados dos autores}

Nome completo: André Andrade Longaray

Filiação institucional: Universidade Federal do Rio Grande - FURG

Departamento: Instituto de Ciências Econômicas, Administrativas e Contábeis - ICEAC

Cargo ou função ocupada: professor Associado - Líder do LabSADi (Laboratório de estudos e pesquisas em sistemas de apoio à decisão)

Endereço completo para correspondência:

Av. Itália, km 08, s/nº - Campus Carreiros - Rio Grande - RS

Cep 96.203-901

Telefones para contato: (51) 9354-4547

e-mail: longaray@yahoo.com.br

Nome completo: Deborah Matheus das Neves Fiussen

Filiação institucional: Universidade Federal do Rio Grande - FURG

Função ou cargo ocupado: estudante de pós-graduação - pesquisadora no LabSADi (Laboratório de estudos e pesquisas em sistemas de apoio à decisão)

Endereço completo para correspondência: Rua Fermino Amaral, 202, Senandes, Rio Grande - RS, Brasil, CEP: 96217-075

Telefones para contato: (53) 3236-4740 / (53) 99090816

e-mail: dfiussen@gmail.com

Submetido em: 01/08/2013

Aceito em: 15/10/2014 